\title{
Silicon with Clusters of Impurity Atoms as a Novel Material for Optoelectronics and Photovoltaic Energetics
}

\author{
M. K. Bakhadyrhanov ${ }^{1}$, U. X. Sodikov ${ }^{1}$, D. Melibayev' ${ }^{2}$, Tuerdi Wumaier ${ }^{3}$, S. V. Koveshnikov ${ }^{1}$, \\ K. A. Khodjanepesov' ${ }^{2}$, Jiangxiang Zhan ${ }^{3}$ \\ ${ }^{1}$ Tashkent State Technical University, Tashkent, Uzbekistan \\ ${ }^{2}$ Turkmenistan State University of Transport Communication, Ashgabat, Turkmenistan \\ ${ }^{3}$ Xinjiang Institute of Engineering, Urumchi, China \\ Email: `bahazed@yandex.com,dmelebay@yandex.com,turdi@ms.xjb.ac.cn
}

How to cite this paper: Bakhadyrhanov, M.K., Sodikov, U.X., Melibayev, D., Wumaier, T., Koveshnikovm, S.V., Khodjanepesov, K.A. and Zhan, J.X. (2018) Silicon with Clusters of Impurity Atoms as a Novel Material for Optoelectronics and Photovoltaic Energetics. Journal of Materials Science and Chemical Engineering, 6, 180-190.

https://doi.org/10.4236/msce.2018.64017

Received: April 11, 2018

Accepted: April 27, 2018

Published: April 30, 2018

Copyright (c) 2018 by authors and Scientific Research Publishing Inc. This work is licensed under the Creative Commons Attribution International License (CC BY 4.0).

http://creativecommons.org/licenses/by/4.0/

\begin{abstract}
The paper presents unique functional capabilities of silicon with nanoclusters of impurity atoms with various characters. It is shown that, depending on the nature of the clusters, it is possible to expand the spectral diapason of sensitivity towards the IR region and obtain silicon with anomalously high negative magnetoresistance $(\Delta \rho / \rho>100 \%)$ at room temperature. The formation of clusters of impurity atoms with different nature and concentration in the lattice of semiconductor materials is a new approach for obtaining bulk-nanostructured silicon with unique physical properties.
\end{abstract}

\section{Keywords}

Silicon, Spectral Range, Elementary Cell, Binary Nanocluster, Quantum Dots, Photovoltaic Cell, Multicascade PV Cell, Spectral Sensitivity, IR Irradiation, Magnetic Properties, Photoconductivity, Nanoscale

\section{Introduction}

Practically all of the main functionalities of existing semiconductor materials have been entirely well studied and used in the sphere electronics [1] [2].

The forward electronics development requires semiconductor materials with the new basic properties, fundamental parameters and physical phenomena in them. At the same time, the development of semiconductor materials science should focus on ensuring the development of new electronics industries: new directions in functional and integral electronics, the use of nanophotonic mate- 
rials in nanoelectronic devices, and also photovoltaic energetics and optoelectronics.

Each of these fields required individual class of materials with certain physical properties and fundamental parameters. So, for instance, to provide cheap and highly efficient fiber-optic communication based on passive optical network technology, it would necessary to create low cost prices of LED emitters in the range of $\lambda=1.5-1.6$ micron, as well as photodetectors with highly sensitive high-speed for working in this spectral region. However, at present, there are practically no existing low cost semiconductor materials and respectively technologies make it possible to massively create such devices [3].

The development of some nanoelectronic directions is determined due to need of developing technology for bulk nanostructured semiconductors with controlled parameters of the structure, composition, and other properties of nanoobjects. Obtaining such materials will allow a creation of new types of materials photon, as well as materials unique functionality of nanoscaled superlattices. However, the modern technology of nanostructure formation also does not allow obtaining such materials on a wide scale [4].

As is known, a low of efficiency of modern industrial silicon photovoltaic cells (up to $20 \%$ ) is associated with inefficient use irradiation of solar energy in the region of the spectrum with the range $\lambda=1.2-3$ micron (about $40 \%$ of the total solar irradiation), and also with the effect thermalization of photogenerated charge carriers associated with the absorption quants of light with the energy $h v>E_{g}$. Some calculations [5] show that the loss of efficiency in single-cascade photovoltaic cells due to such effects is about $50 \%$.

The high efficiency of multicascade photovoltaic cells which based on semiconductor compounds of $\mathrm{A}^{\mathrm{III}} \mathrm{B}^{\mathrm{V}}$ [6] are subjected to quite a complicated technology for their fabrication and require expensive equipment, which finally determines their high cost. Apart from this, their widespread application in terrestrial conditions is of particular difficulty.

There is some question arises: can we create semiconductor materials, in terms of their physical properties and fundamental parameters, to ensure the development of modern electronics and photovoltaic energetics?

\section{Materials and Methods}

Studies carried out in the last 15 - 20 years have shown the technology of "low-temperature" diffusion doping developed [7] [8] [9] [10] [11], with subsequent annealing of the material under certain conditions, which has made it possible not only to significantly change the state of impurity atoms in the silicon lattice, but also to obtain silicon with absolutely new electrical and photoelectric properties. The result of application of the developed technology consists of formation atomic or binary, monomolecular and more complex clusters of impurity atoms in the lattice of silicon [12]. Such nanostructures in the bulk of a silicon lattice with controlled concentration, size, composition and structure 
make it possible to change a lot of properties of the original silicon, including the structure and size of the forbidden band, carrier mobility, and others.

Depending on the nature of impurity atoms, it is also possible to form magnetic and multicharged atomic clusters [13], which have a sufficient magnetic moment and a large electrical potential, as well as binary (consisting of atoms of different types) clusters with various sizes, structure and composition, and, consequently, with their own basic features. Such nanoclusters manifested themselves as quantum dots with special magnetic, optical and electrical properties and, respectively new functional possibilities of their application.

The sample was a p-type single-crystalline silicon with a resistivity of $\rho=3-5$ $\Omega * \mathrm{~cm}$, with an oxygen concentration $\mathrm{N}=4 \times 10^{17} \mathrm{~cm}^{-3}$, a dislocation density of $\mathrm{S} \sim 10 \mathrm{~cm}^{2}$, and a surface orientation. Samples with nanoclusters of nickel and manganese atoms were prepared according to the technology developed [14], the maximal diffusion temperature of nickel was $\mathrm{T}=1200^{\circ} \mathrm{C}$ and time $\mathrm{t}=30 \mathrm{mi}$ nutes, for manganese $\mathrm{T}=1080^{\circ} \mathrm{C}$ for 40 minutes. To form binary clusters, the samples were first doped with sulfur at $\mathrm{T}=1200^{\circ} \mathrm{C}$ for 15 hours, then manganese diffusion was carried out at $\mathrm{T}=1160^{\circ} \mathrm{C}$ for 40 minutes. After alloying, the samples were subjected to additional thermal annealing at a temperature of $1100^{\circ} \mathrm{C}$ for 2 hours. Dimensions of samples $8 \times 3 \times 0.1 \mathrm{~mm}^{3}$ electrical parameters before and after diffusion were investigated by the Hall effect method, and the state of the clusters by the methods of AFM, EPR, and also states of clusters are observed in the bulk and surface with an infrared microscope. Photovoltaic cells were created using conventional technology by diffusing phosphorus at a temperature of $\mathrm{T}=1050^{\circ} \mathrm{C}$ for 30 minutes.

\section{Results and Discussion}

In Figure 1 shows the state of impurity nickel atoms in silicon after diffusion, which was studied by means of an infrared microscope. The cooling rate was $\mathrm{T}=$ $100^{\circ} \mathrm{C} / \mathrm{s}$. Similar samples were subjected to additional annealing at $\mathrm{T}=850^{\circ} \mathrm{C}$ and $\mathrm{T}=650^{\circ} \mathrm{C}$ during those hours (Figure $1(\mathrm{a})$ ). As can be seen in the diffusion-doped samples, a uniform distribution of dark points is observed that indicates the formation of clusters of nickel impurity atoms with a size $\mathrm{d} \leq 0.5 \mathrm{mi}$ cron and a density of $\mathrm{S} \sim 10^{7}-10^{8} \mathrm{~cm}^{-2}$ as a result of their self-organization.
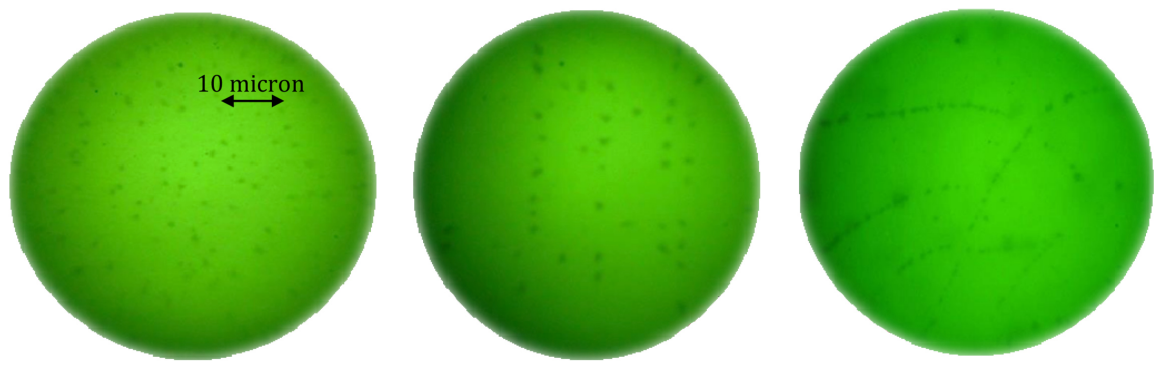

Figure 1. State of clusters of Ni atoms in silicon. (a) After diffusion; (b) After thermal annealing at $\mathrm{T}=850^{\circ} \mathrm{C}$; (c) After thermal annealing at $\mathrm{T}=650^{\circ} \mathrm{C}$. 
From the surface of the samples obtained, 50 micron silicon was removed step by step to the middle of the sample thickness and the state of the clusters was studied using an IR microscope.

As the results showed, no significant changes were observed. This means that the clusters are distributed uniformly throughout the bulk of the crystal. At the same time, in the samples subjected to additional thermal annealing at $\mathrm{T}=$ $850^{\circ} \mathrm{C}$ an interesting phenomenon is observed, that is, the clusters are enlarged and their ordering begins (Figure $1(\mathrm{~b})$ ). This process intensifies with a decrease in the annealing temperature and practically reaches its equilibrium state at $\mathrm{T}=$ $650^{\circ} \mathrm{C}$ (Figure $1(\mathrm{c})$ ). These results show that changing the conditions for temperature annealing can control not only the dimensions of the clusters, but also their state in the lattice. These amazing phenomena require more detailed studies, since the mechanism for the formation, integration and ordering of clusters in certain directions has not yet been entirely studied. Preliminary results showed that the cluster-silicon structure is a Schottky barrier with an ideal I-V characteristic and special thermal and optical properties.

As is known in silicon [15], nanoclusters are formed consisting of four manganese atoms located in the vicinity interstices around the boron atom. Based on the results of the investigation of the state of atoms in a silicon lattice by the EPR method, AFM and electrical measurements, it was shown that to maximize the participation of manganese atoms in the formation of clusters, it is necessary to satisfy the condition $\mathrm{N}_{\mathrm{Mn}} \leq 2 \mathrm{~N}_{\mathrm{B}}$ (where $\mathrm{N}_{\mathrm{Mn}}$ is the concentration of electroactive manganese atoms and $\mathrm{N}_{\mathrm{B}}$ is the boron concentration). The samples (initially were a p-type single-crystalline silicon with a resistivity of $\rho=3 \Omega * \mathrm{~cm}$ ) after diffusion of manganese are of p-type with $\rho \sim(3-4) 10^{3} \Omega * \mathrm{~cm}$. In them, the residual, that is, non-compensated, hole concentration was $\mathrm{p}=(1.5-2) * 10^{13} \mathrm{~cm}^{-3}$ at $\mathrm{T}=300^{\circ} \mathrm{C}$. In such samples, the manganese atoms are in the form of $(\mathrm{Mn})_{2}$ and accordingly one can assume that the manganese clusters are in the maximum-multicharged state $\left[(\mathrm{Mn})_{4}^{+8} \mathrm{~B}^{-1}\right]^{+7}[16]$. In this case, the band structure of silicon with multicharged clusters can be represented as follows (Figure 2), which explains entirely the characteristics of the photoelectric properties of such materials.

The spectral dependence of the photoconductivity of the samples under study is shown in Figure 3. As can be seen, a number of anomalous phenomena are

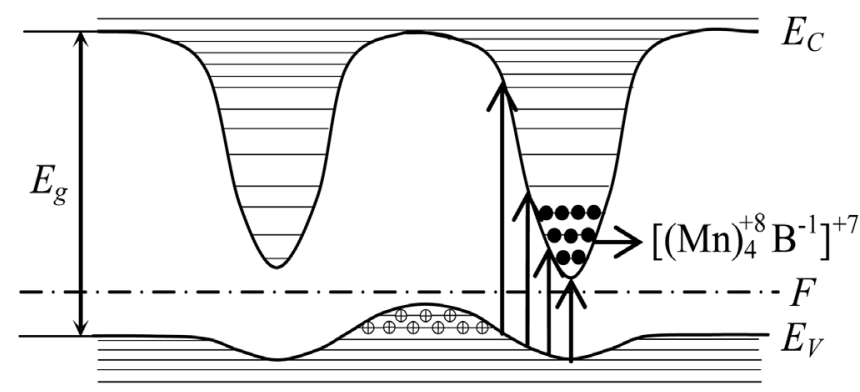

Figure 2. The band structure of silicon with multicharged clusters. 


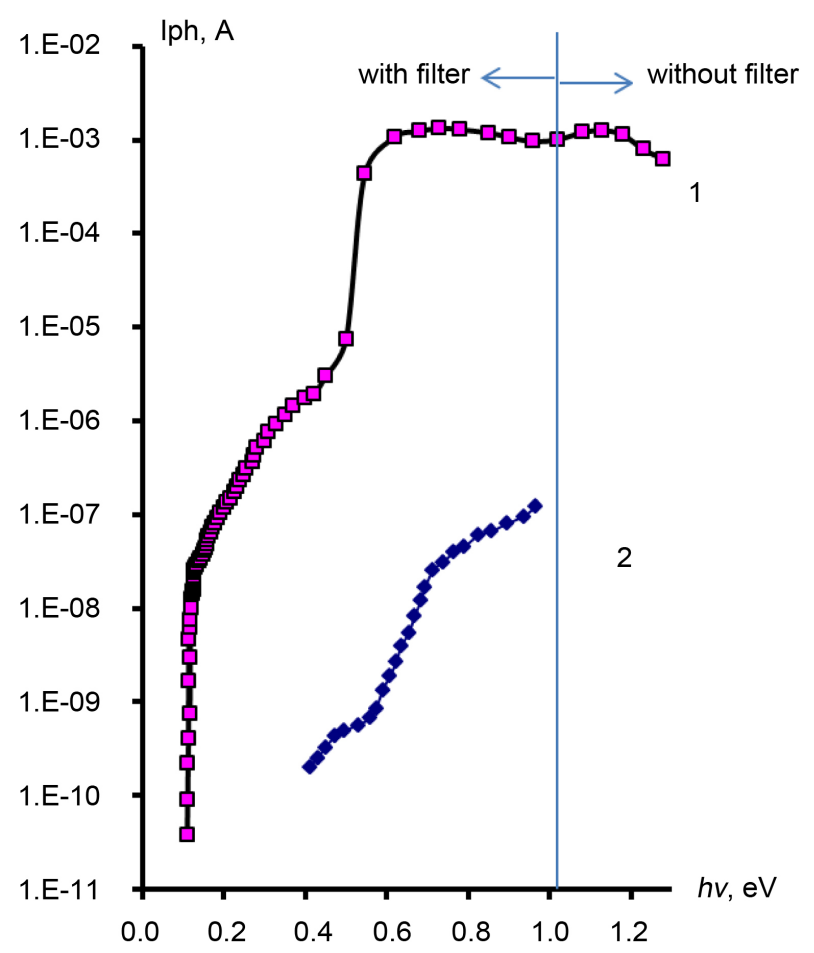

Figure 3. Spectral dependence of photoconductivity (PC) with the sample of multicharged nanoclusters of manganese atoms (1) and a similar sample without formation of nanoclusters (2).

observed in them. Firstly, the photoresponse begins at $\mathrm{h} \lambda=0.12-0.13 \mathrm{eV}(\lambda \sim$ 10 micron, at $\mathrm{T}=100 \mathrm{~K}$ ), which can not be explained from the standpoint of electron statistics. In addition, as known, manganese atoms in silicon create two donor levels with an ionization energy $\mathrm{E}_{1}=\mathrm{E}_{\mathrm{C}}-0.27 \mathrm{eV}, \mathrm{E}_{2}=\mathrm{E}_{\mathrm{C}}-0.5 \mathrm{eV}$ [17], and in the samples under study if these levels are maintained, they will be $100 \%$ empty, since the samples were of $p$ type. Therefore, we can say that the observed photoresponse is associated only with the transition of electrons from the valence band to the energy levels near the valence band. Secondly, as seen, the value of the photocurrent continuously increases with increasing energy of the incident photon up to $\mathrm{h} \lambda=0.7-0.8 \mathrm{eV}(\lambda \sim 1.5-1.6$ micron). This behavior of the photocurrent can not also be explained by the presence of any discrete energy levels in the forbidden band in silicon. Third, in the samples under study in the region $\mathrm{h} \lambda=0.7-0.8 \mathrm{eV}$ ( $\lambda=1.5-1.6$ micron), an anomalously large impurity conductivity is observed, the value of which practically does not differ from the value of the photocurrent in the intrinsic conductivity region $(\mathrm{h} \lambda \geq 1.12 \mathrm{eV})$. This behavior of photoconductivity can be only in the case of the formation of a subband or mini zone, which provides interband optical transitions. The experimental results obtained testify to the existence of a rearrangement of the band structure of silicon, where multicharged clusters are localized (Figure 3). The spectral dependence of the photoconductivity of silicon doped with manganese atoms without the formation of clusters (Figure 3 of curve 2) can serve as a 
proof of this.

The "low-temperature" diffusion technique developed [16] has made it possible to form magnetic clusters of manganese and gadolinium atoms in a silicon lattice. The presence of such magnetic clusters was proved by the investigation of the state of impurity atoms by the EPR method. In the samples with magnetic clusters of manganese atoms, a number of new magnetic phenomena were discovered. Anomalously large magnetoresistance $(\Delta \rho / \rho>100 \%)$ was found in them at room temperature, the magnitude of which is mainly determined via concentration and nature of the magnetic clusters (Figure 4), while in other semiconductor materials, negative magnetoresistance (NMR) was detected at $\mathrm{T}=4.2-100 \mathrm{~K}$, and its value does not exceed $10 \%$ [17].

Moreover, a very interesting and new phenomenon was discovered-the possibility of controlling the value of NMR over a wide range of values, including even the possibility of changing the sign of the MR (the transition from NMR to positive MR) under the influence of illumination in the region of intrinsic absorption. As was shown in Figure 5, range intensity of illumination from 1 to 80 lux, the value of the NMR decreases from $100 \%$ to 0 , and when the sample is illuminated above 80 lux, a positive MR takes place, that is, the sign of the MR changes.

These results indicate that a photomagnetic phenomenon is observed in the materials under study, which is absent in ordinary magnetic semiconductors. Therefore, we can say that these amazing phenomena in silicon with magnetic clusters will lay the foundation for a new scientific direction in the field of semiconductor materials science with the possibility of using them for developing fundamentally new photomagnetic devices.

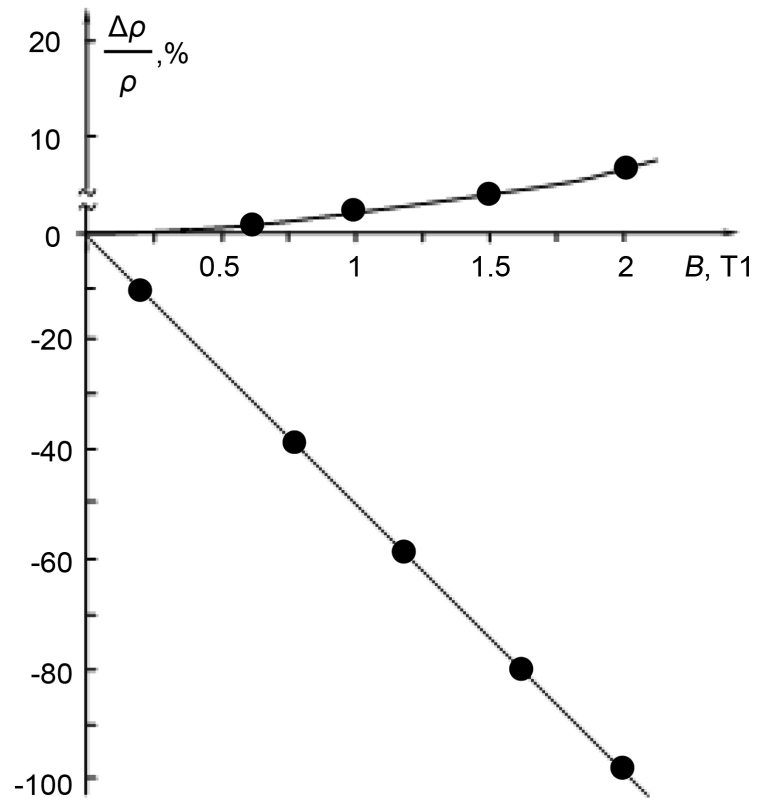

Figure 4. Effect of anomalously large (more than 100\%) negative magnetoresistance (NMR) at room temperature. 


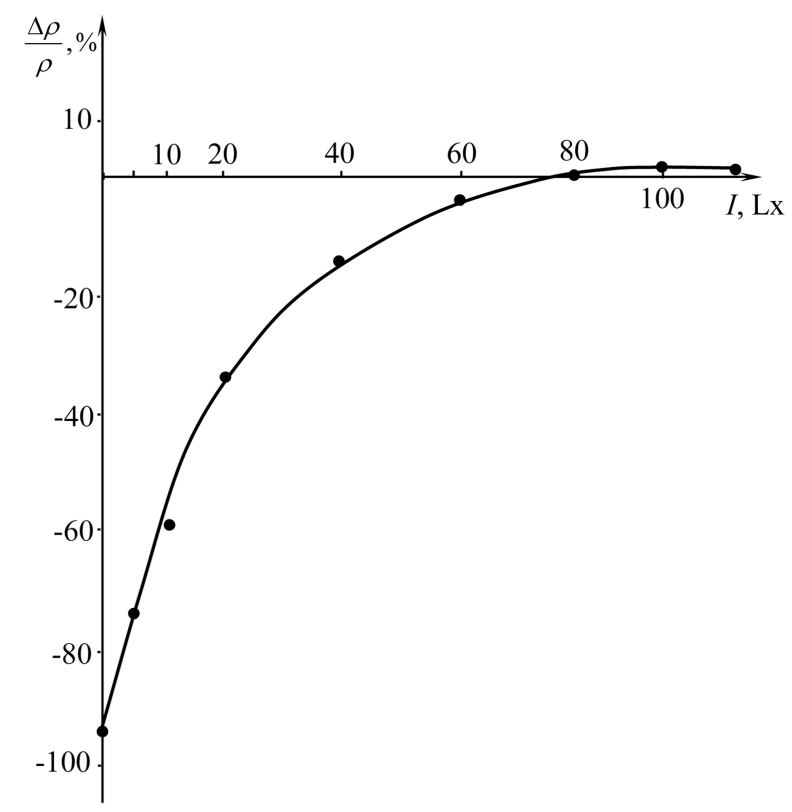

Figure 5. Changes in NMR on intensity of illumination.

The developed technology of successive doping of silicon with impurity atoms of sixth group (sulfur, selenium) and iron group with subsequent heat annealing under certain thermodynamic conditions made it possible to form binary clusters in the silicon lattice, creating nuclei of a new phase in the bulk-new elementary cells in silicon. At the same time, silicon, sulfur and manganese atoms are located at the adjacent lattice sites and formed electrically neutral molecules as a type $\mathrm{S}^{++} \mathrm{Mn}^{--}$. As a result, a new elementary lattice cell of the type $\mathrm{Si}_{2} \mathrm{~S}^{++} \mathrm{Mn}^{--}$is formed (Figure 6(a)). Such a cell does not violate tetrahedral bonds in silicon and is built into the lattice without violating its structure. The formation of such cells provides a more thermodynamically advantageous state of the system and substantially increases the solubility of these impurities in silicon.

All this stimulates their self-organization and self-restructuring. The results of the research show, with an increase in the concentration of impurities, the association of elementary cells of the $\mathrm{Si}_{2} \mathrm{~S}^{++} \mathrm{Mn}^{--}$type occurs, with the formation of more complex structures that form nucleus of a new phase (nanocrystals) of sulphides, selenides or tellurides (SMn compounds) in the silicon lattice (Figure 6(b) and Figure 6(c)). Each nanoclusters of a new phase, due to the difference in their dimensions, has its own fundamental parameters, which differ substantially from both the parameters of silicon and the parameters of the new phase. It should be noted that choosing the pairs from the elements of the sixth and transition groups, taking into account their physical and chemical parameters, as well as the diffusion coefficient in silicon, one can control the composition, structure, concentration of new elementary cells, and their fundamental parameters. This means that by creating such binary nanoclusters in a silicon lattice, the spectral region of the photosensitivity can be substantially expanded both in the direction of the IR and in the direction of the photon energies $h v>\mathrm{E}_{\mathrm{g}}$. 


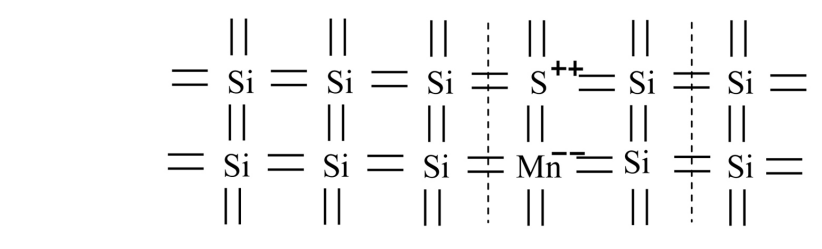

(a) Lattices of $\mathrm{Si}$ and $\mathrm{Si}_{2} \mathrm{~S}^{++} \mathrm{Mn}^{--}$

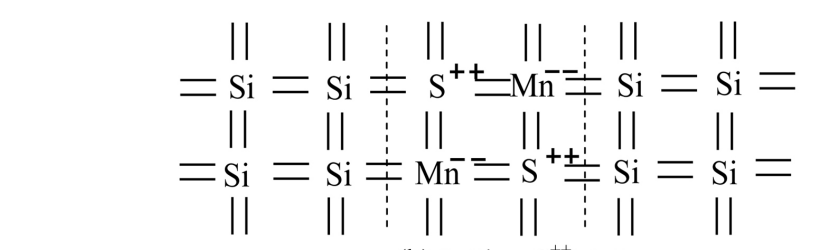

(b) Lattices $\mathrm{S}^{++} \mathrm{Mn}^{--}$

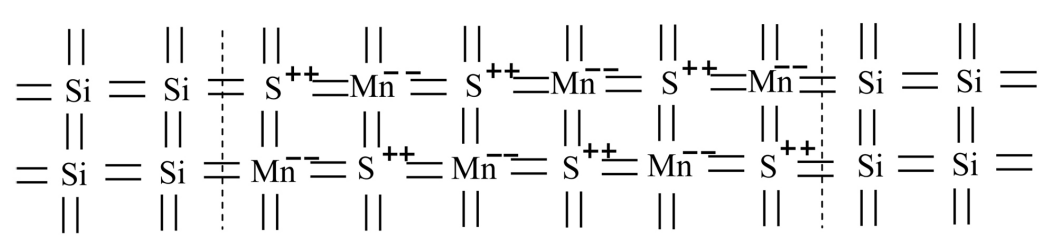

(c) Nanocrystals $\mathrm{S}^{++} \mathrm{Mn}^{--}$

Figure 6. Formation of new elementary cells of the type $\mathrm{Si}_{2} \mathrm{~S}^{++} \mathrm{Mn}^{--}$(a), $\mathrm{S}^{++} \mathrm{Mn}^{--}$ (b), and their associations (c) in the silicon lattice.

This is due to the fact that unlike silicon, new phases can have a direct-band structure, which increases the probability of interband optical transitions by several orders of magnitude.

Therefore, it can be argued that silicon materials with binary nanoclusters can be used as promising materials for photovoltaic energetics, allowing them to create more efficient photovoltaic cells [18] [19] [20] replacing expensive multicascade structures on their basis. This can be proved by the results of a study of photovoltaic cells with binary clusters of SMn composition.

There is main parameters $\left(I_{s c}\right.$ and $\left.V_{o v}\right)$ were investigated in a special setup, which practically completely excluded light from the incident solar radiation with a quantum energy corresponding to intrinsic absorption in silicon. Lighting of the photovoltaic cells was carried out through a $5 \mathrm{~mm}$ thick silicon filter made of high-resistance silicon providing absorption of radiation with $h v>E_{g}$ but transmitting more than $30 \%$ of the long-wavelength infrared solar radiation. As a control, a solar cell was used for industrial production.

As can be seen from Table 1, the contribution of the long-wave part $\left(h v<E_{g}\right)$ of solar irradiation for an element of industrial production does not exceed $0.5 \%$ $(1 / 203)$, and for a sample with a concentration of sulfur and manganese $10^{17}$ $\mathrm{cm}^{-3}$ reaches $1 / 40-2.5 \%$, that is, increases fivefold. Taking into account the reflection coefficient of the infrared radiation of the sun from the front and rear surfaces of the silicon filter (not less than 70\%), it is possible to assume an increase in the short-circuit current of photovoltaic cells with clusters by $8 \%$. Then the absolute increase in the efficiency of such a photovoltaic cell may be $1 \%$.

Figure 7 shows the spectral dependence of the short-circuit current of the ex- 
perimental and the reference photovoltaic cell obtained on the monochromatic spectrometer of IKS-21.

As can be seen from the figure, an appreciable short-circuit current appears even at $h v>0.4 \mathrm{eV}$ ( $\lambda=3$ micron). All these data allow us to state that when developing optimal alloying conditions using specially selected impurity atoms, it is possible to expand the spectral region of silicon sensitivity substantially and, on this basis, to develop more efficient solar cells.

The sensitivity of photovoltaic cells made on the basis of silicon with binary

Table 1. Dependence of the IR sensitivity of photovoltaic cells with binary clusters on the concentration of impurities Se and Mn.

\begin{tabular}{cccccc}
\hline & & \multicolumn{4}{l}{ Photovoltaic cells based on binary cluster } \\
\cline { 3 - 5 } $\begin{array}{c}\text { In the presence of } \\
\text { filter }\end{array}$ & Industrial photovoltaic cell & I & II & III & IV \\
\cline { 3 - 5 } & 203 & 170 & 150 & 90 & 35 \\
$I_{S i}$ & - & $10^{16}$ & $3 \times 10^{16}$ & $5 \times 10^{16}$ & $10^{17}$ \\
\hline
\end{tabular}

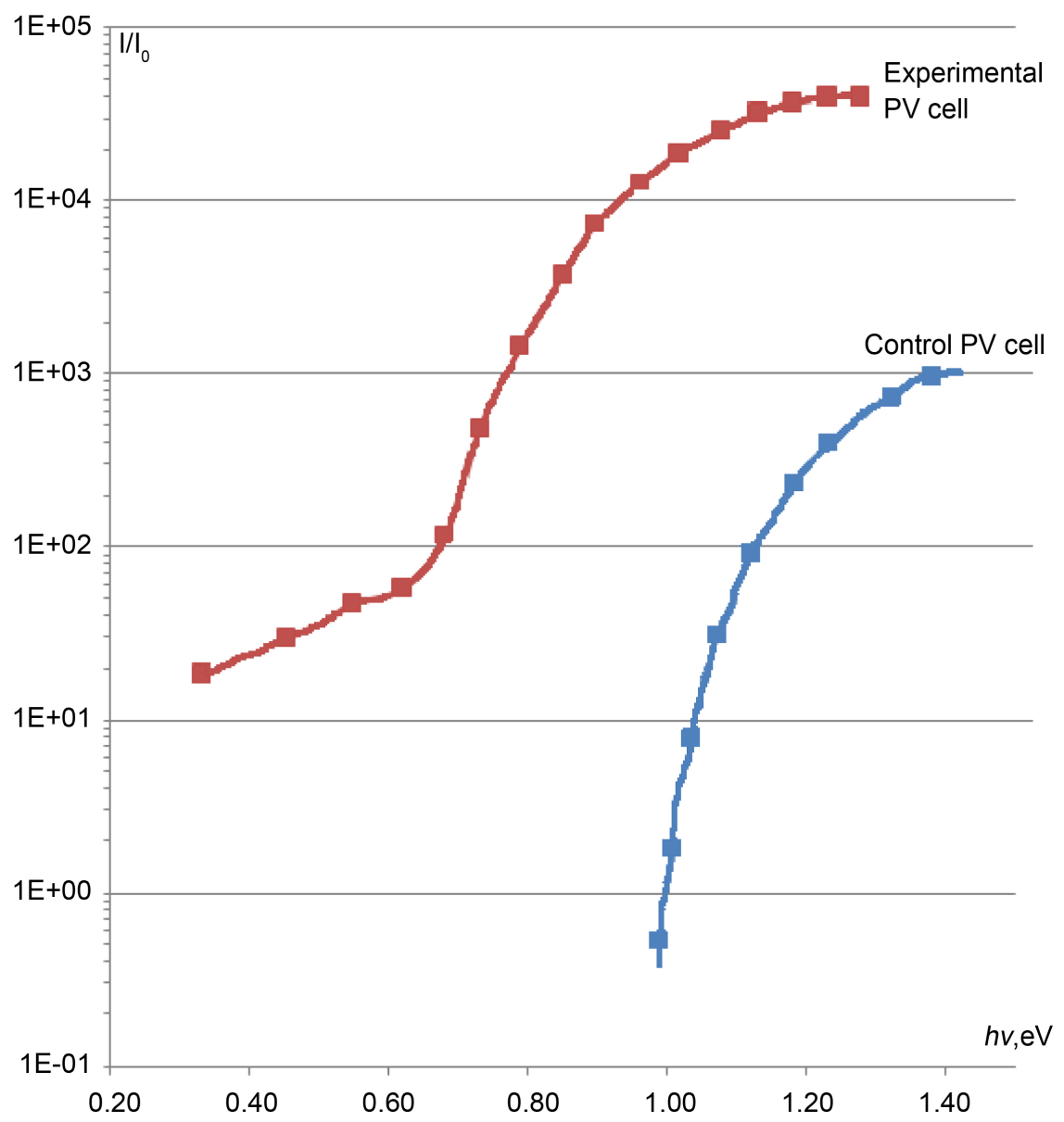

Figure 7. Spectral dependence of the short-circuit current of the experimental and control photovoltaic cell. 
clusters in the long-wave part of the IR spectral region ( $\lambda=3$ micron) will allow them to be used as IR photodetectors necessary for creating pyrometric temperature with the range $500-900 \mathrm{~K}$.

\section{Conclusion}

All of the results obtained give reason to believe that silicon with nanoclusters of various nature is indeed a unique material in the field of semiconductor materials science. Therefore, the main task is the further development of technologies for obtaining such materials with controlled properties and composition of clusters, as well as the study of their electrical, photoelectric optical and magnetic properties, which will allow us to correctly estimate their functional capabilities for photoenergetics and electronics.

\section{Acknowledgements}

This work was financially supported by Science and Technology projects Project Proposal for Uzbek-China Research Program "National Key R\&D Program of China”, №2016YFE0120900.

\section{References}

[1] Yu, P.Y. and Cardona, M. (2002) Fundamentals of Semiconductors: Physics and Materials Properties. 3rd Edition, Springer, Berlin.

[2] Sze, S.M. (1993) Physics of Semiconductor Devices. 2nd Edition, Bell Laboratories, Murray Hill Incorporated, New Jersey, Wiley Easter Limited, New Delhi.

[3] Buonassisi, T. Introduction to Fundamentals of Photovoltaics. http://ocw.mit.edu

[4] Poole Jr., C.P. and Owens, F.J. (2003) Introduction to Nanotechnology. John Wiley \& Sons, Hoboken.

[5] Fahrenbruch, A. and Bube, R. (1993) Fundamentals of Solar Cells. Photovoltaic Solar Energy Conversion. Academic Press, New York, 90-102.

[6] Ж.И. Алферов. (2011) Избранные труды нанотехнологии. Издательский дом Магистр-пресс, Москва,.

[7] Milvidskii, M.G. and Chaldishev, V. (1998) Nanoscale Atomic Clusters in Semiconductors as a new Approach to Formation of Materials Properties. Journal of Semiconductors, 32, 513-522.

[8] Sekuguchi, T., Yoshida, S. and Itoh, K.M. (2005) Self-Assembly of Parallel Atomic Wires and Periodic Clusters of Silicon on a Vicinal Si(111) Surface. Physical Review Letters, 95, Article No: 106101. https://doi.org/10.1103/PhysRevLett.95.106101

[9] Komarov, F.F., Velichko, O.I., Dobrushkin, V.A. and Mironov, A.M. (2006) Mechanisms of Arsenic Clustering in Silicon. Physical Review B, 74, Article No. 035205. https://doi.org/10.1103/PhysRevB.74.035205

[10] Xiao, C.Y., Blundell, J., Hagelberg, F., William, A. and Lester, J. (2004) Silicon Clusters Doped with an Yttrium Metal Atom Impurity. International Journal of Quantum Chemistry, 96, 416-425. https://doi.org/10.1002/qua.10735

[11] Bakhadyrhanov, M.K., Aypov, K.S., Iliev, K.M., Mavlonov, G.K. and Sattorov, O.E. (2009) Effect of Electric Field, Illumination, and Temperature on the Negative 
Magnetoresistance of Low-Temperature-Diffusion-Doped Silicon. Technical Physics Letters, 35, 741-744.

[12] Bakhadyrhanov, M.K., Askarov, S.I. and Norkulov, N. (1994) Some Features of Chemical Interaction between a Fast Diffusing Impurity and a Group VI Element in Silicon. Physica Status Solidi A, 142, 339-346.

https://doi.org/10.1002/pssa.2211420206

[13] Bakhadyrhanov, M.K., Aypov, K.S., Mavlonov, G.K. and Isamov, S.B. (2010) Negative Magnetoresistance in Silicon with Manganese-Atom Complexes [Mn $]_{4}$. Semiconductors, 44, 1145-1148. https://doi.org/10.1134/S106378261009006X

[14] Abdurakhmanov, B.A., Bakhadyrhanov, M.K., Aypov, K.S., Iliev, H.M., Saitov, E.B., Mavlonov, A. and Kamalov, U.H. (2014) Formation of Clusters of Impurity Atoms of Nickel in Silicon and Controlling Their Parameters. Nanosciens and nanotechnology, 4, 23-26.

[15] Bakhadyrhanov, M.K. and Isamov, S.B. (2016) IR Photodetectors Operating under Background Illumination. Technical Physics, 61, 458-460. https://doi.org/10.1134/S106378421603004X

[16] Zhang, J., Ba, W.-Z., Chen, Z.-Y., Cong, X.-Y., Tao, M.-D. and Bakhadyrkhanov, M.K. (2014) Highly Compensated Si: Light Sensitive Characteristic. Journal of Electronic Components \& Materials, 23, 20-23.

[17] Milnes, A.G. (1973) Deep Impurities in Semiconductors. Carnegie Mellon University, John Wiley \& Sons, New York.

[18] Yunusov, Z.A., Yuldashev, S.U., Igamberdiev, K.T., Kwos, Y.H., Kang, T.W., Bakhadyrhanov, M.K., Isamov, S.B. and Zikrillaev, N.F. (2014) Ferromagnetic States of P-Type Silicon Doped with Mn. Journal of the Korean Physical Society, 64, 1461-1465. https://doi.org/10.3938/jkps.64.1461

[19] Bakhadyrkhanov, M.K., Mavlyanov, A.S., Sodikov, U.K. and Khakkulov, M.K. (2015) Silicon with Binary Elementary Cells as a Novel Class of Materials for Future Photoenergetics. Journal of Applied Solar Energy, 51, 258-261. https://doi.org/10.3103/S0003701X1504009X

[20] Bakhadyrhanov, M.K., Valiev, S.A., Zikrillaev, N.F., Kaveshnikov, S.V., Saitov, E.B. and Tachilin, S.A. (2016) Silicon Photovoltaic Cells with Clusters of Nickel Atoms. Journal of Applied Solar Energy, 52, 278-281. https://doi.org/10.3103/S0003701X1604006X 